\title{
CONSAGRANDO A LOS CIUDADANOS. PROCESOS ELECTORALES COMPARADOS EN LA CAMPAÑA DE BUENOS AIRES DURANTE LA PRIMERA MITAD DEL SIGLO XIX
}

POR

\author{
SOL LANTERI \\ Doctora en Historia, Becaria Postdoctoral del CONICET \\ y Docente del Instituto Ravignani/UBA. Buenos Aires, Argentina \\ DANIEL SANTILLI \\ Doctor en Historia, Investigador \\ y Docente del Instituto Ravignani-UBA. Buenos Aires, Argentina
}

El objetivo del trabajo es realizar un primer análisis comparativo de las prácticas electorales en la campaña de Buenos Aires desde la instauración de la ley de sufragio "amplio» en 1821 hasta el rosismo inclusive, a partir del estudio de jurisdicciones politicas diferenciadas como los partidos (mínima jurisdicción política) de Quilmes y Azul-Tapalqué, distanciadas geográfica e históricamente. A través de correspondencia, actas y listas electorales, etc., se examina de forma confrontada sus comportamientos electorales vinculados a los aspectos socio-demográficos, económicos y culturales, recalcando la importancia de los sectores medios y subalternos, y de la negociación y el consenso en el proceso.

Palabras Clave: Campaña de Buenos Aires, $1 .{ }^{a}$ mitad del siglo XIX, procesos electorales, negociación y reciprocidades.

\section{INTRODUCCIÓN}

En las últimas décadas, la historia política ha sido una de las líneas disciplinares que más se ha renovado. De la mentada lectura esencialista decimonónica sobre la prelación histórica de la nación al Estado se ha transitado a una apertura de los problemas, los enfoques y las perspectivas de análisis que com- 
plejizan con creces a la tradición anterior. Así, el estudio de «la política» ha dado lugar al examen de «lo político» en sus múltiples dimensiones, con la inclusión de las variables cultural, simbólica, conceptual, etc., así como de la praxis social y una ampliación cuantitativa y cualitativa de los sujetos considerados, que de estar basados habitualmente en las elites, se han extendido a los sectores medios y subalternos; al análisis de sus especificidades e interrelaciones $^{1}$. Asimismo, aquellas coyunturas que otrora se concebían sólo como meras etapas de un proceso teleológico conducente a la construcción y consolidación de los Estados nacionales modernos, hoy son estudiadas dentro de las características propias que presentan. En este marco, el estudio de la ciudadanía política y la formación de los sistemas republicanos en Iberoamérica constituyen una de las líneas de análisis más fecundas, especialmente desde la reapertura del sistema democrático en Argentina y en otras latitudes ${ }^{2}$.

La retroversión de la soberanía generada por el derrumbe imperial y las revoluciones independentistas creó una nueva cultura política en el contexto iberoamericano, donde salvo en Brasil, en la mayoría de los nuevos Estados se implementaron sistemas republicanos de gobierno, con ciertas singularidades, pero basados en los conceptos de soberanía popular y representación política ${ }^{3}$. En el Río de la Plata, luego de los intentos centralistas de la primera década revolucionaria se conformaron Estados provinciales, que unidos en un sistema confederal a partir del Pacto Federal de 1831, tuvieron autonomía en el forjamiento de sus bases de poder institucionales, sociales, económicas y militares, siendo junto a la gran inestabilidad política y la crisis de legitimidad post-revolucionaria, algunos de los problemas más relevantes que estas noveles entidades del interior y del litoral tuvieron que resolver, inclusive durante el gobierno de caudillos como Juan Manuel de Rosas.

En la provincia de Buenos Aires, las reformas implementadas por el gobierno de Martín Rodríguez, lapso conocido como la «feliz experiencia», instituyeron, entre otras cuestiones, la ley electoral de 1821, que implicó un nuevo concepto de representación política, basado en la realización de elecciones regulares directas para los diputados de la Sala de Representantes — que a la vez era el organismo legislativo y el encargado de elegir al gobernador provincial

1 Echeverría y Lionetti, 18 (Tandil, 2003): 191-199.

2 Sábato, 106: 4 (EE.UU., 2001): 1290-1315. Quijada, Bernand y Schneider, 2000. Sábato y Lettieri (comps.), 2003. Annino (coord.), 1995. Sevilla Soler (coord.), 1999. Sábato, (coord.), 1999. Malamud (coord.), 2000, respectivamente.

3 Ibid.

4 Halperín Donghi, 1972. Chiaramonte, 26/102 (Buenos Aires, 1986): 175-196; 1991; 1997. Goldman y Salvatore (comps.), 1998. Goldman (dir.), 1998. 
cada tres años - con duración anual y en una ampliación de los electores activos a todos los varones libres mayores de veinte años (o menores si fueran emancipados), naturales del país o extranjeros avecindados — sin requisitos de propiedad, instrucción o profesión-, confirmando además la incorporación de los habitantes de la campaña a la vida política provincial que regía desde el estatuto de 1815, a la par que les otorgaba representación ${ }^{5}$. La ley de sufragio «amplio» o «universal» - tal como ha sido denominada por algunos investigadores - constituyó una verdadera novedad en el contexto latinoamericano y aún occidental, ya que, cuando se concedía, se aplicaban severas restricciones al derecho a elegir y ser elegido ${ }^{6}$.

Esta normativa fue continuada con algunas reformas durante la etapa de Rosas (1829-32 y 1835-52), aún en su segundo período, cuando a partir de 1835 asuma la gobernación provincial con la «suma del poder público» y las «facultades extraordinarias» sin limitación temporal. En 1835, el mandato del gobernador fue extendido a cinco años, se incrementó la representación de la campaña por sobre la ciudad en la Sala mediante la ley de 1832 y la elección de sus diputados estuvo digitada por el ejecutivo provincial a través de la confección de una lista única de candidatos, para evitar el faccionalismo y la confrontación política propios del período anterior. Pero pervivió el desarrollo de elecciones regulares y plebiscitos para que representantes y, eventualmente, el gobernador sean refrendados por el voto. Por lo que el total de sufragantes coincidía, usualmente, con el de los escrutinios obtenidos por cada candidato en los comicios, refiriendo a la importancia que para el rosismo tenía la legitimación popular anclada en la voluntad general ${ }^{7}$.

De hecho, nuevas interpretaciones sobre la temática de los caudillismos rioplatenses se refieren a la importancia de la legalidad y la legitimidad en la articulación de su poder, matizando otros atributos provenientes del ideario de Sarmiento otorgados a aquéllos, como la arbitrariedad y el uso exclusivo de la coerción, la anarquía, la falta de institucionalidad de sus bases de poder, etc. ${ }^{8}$. Algunas investigaciones recientes arrojan luz sobre las políticas implementadas por Rosas para construir una autoridad hegemónica que le permitió liderar la provincia y la Confederación Argentina hasta su caída en 1852, imponiéndose a la gran inestabilidad abierta por el proceso revolucionario, e incluso enfrentando a otros sectores del mismo federalismo porteño. Entre las medidas

5 Halperín Donghi, 1972. Ternavasio, 1999: 119-141; 2002. Cansanello, 5 (Rosario, 2001): 143-170; 2003.

6 Ternavasio, 2002. Halperín, 1972, respectivamente. Ibid. cita 2. Rosanvallon, 1999.

7 Ternavasio, 1999: 119-141; 2002.

8 Goldman (dir.), 1998. Goldman y Salvatore (comps.), 1998. 
pueden mencionarse las relaciones entabladas con otros gobernadores provinciales y la elite económico-social, su política económico-fiscal, la mazorca urbana, la instauración de instituciones y autoridades políticas y militares en la frontera, su política hacia los grupos indígenas, la cesión de tierras públicas a sectores medios y/o subalternos, el desarrollo de fiestas y rituales cívicos, federales y religiosos, prácticas discursivas, entre otras ${ }^{9}$.

En lo referido propiamente al sistema político-electoral, el estudio efectuado por Ternavasio ha sido pionero, mostrando, entre otras cuestiones, la complejidad y los avatares del decurso de un régimen de competencia entre miembros de las elites a partir de 1821 a uno de corte «unanimista» - es decir, de preeminencia exclusiva de la facción federal rosista sobre el resto y una única lista de candidatos susceptibles de ser elegidos por el voto - cristalizado bajo el segundo mandato de Rosas. Si bien la autora también destacó la relevancia del sufragio como vía de legitimación del régimen, el rol de las autoridades y «sectores intermedios» en la movilización electoral y la ampliación de la «frontera política» en los partidos ${ }^{10}$ fronterizos formados al calor de la «expansión ganadera», no profundizó el análisis de la práctica efectiva del sufragio en la campaña, en el marco de una investigación orientada hacia otros objetivos y realizada desde un enfoque centralmente institucionalista, entre otras sobre el tema ${ }^{11}$. Con todo, esta carencia ha comenzado a saldarse recientemente con el desarrollo de estudios realizados para los partidos de Areco, Quilmes y Azul-Tapalqué, entre otros en curso ${ }^{12}$. En efecto, el análisis de los procesos electorales en el mundo rural post-revolucionario es particularmente relevante, pues es dable destacar que el proceso de fortalecimiento del Estado provincial en la campaña bonaerense fue paralelo al de «expansión ganadera» en la frontera austral, e implicó la necesidad de incorporar nuevos recursos como las tierras y controlar y disciplinar a la población rural, mediante la fundación de pueblos y estructuras de poder institucional, la extensión de la ciudadanía política y la obligatoriedad del servicio miliciano, entre otros ${ }^{13}$.

En base a estas consideraciones, el objetivo de este trabajo es realizar un primer análisis comparativo de las prácticas electorales en la campaña de Bue-

9 Gelman, 11 (Castellón, 2004b): 27-44. Gelman y Santilli, 3, 2006. Di Meglio, 12 (Rosario, 2008): 69-90. Ratto, LXIII/227 (Madrid, 2003): 191-222. Infesta, 2003. Salvatore, 2003.

10 Mínima divisón política, administrativa y judicial en que se divide el territorio de la provincia de Buenos Aires.

11 Ternavasio, 2002. Cansanello, 5 (Rosario, 2001): 143-170. Chiaramonte, 1999: 94-116.

12 Garavaglia, 27 (Buenos Aires, 2005): 49-74. Santilli, 12 (Rosario, 2008a): 41-67. Lanteri, 12 (Rosario, 2008a): 15-40, respectivamente. Para el caso de Luján ver Galimberti, 2009.

13 Cansanello, 35 (Colonia, 1998): 159-187. Halperín Donghi, 3 (Buenos Aires, 1963): 57-110. Barral y Fradkin, 27 (Buenos Aires, 2005): 7-48. 
nos Aires desde la implementación de la ley de 1821 incluyendo el cambio de sentido impuesto por el rosismo, mediante los casos de Quilmes y Azul-Tapalqué. Hemos escogido a estas dos jurisdicciones por ser bien diferentes en cuanto a sus características poblacionales y económicas, estando ubicadas en la campaña cercana a la ciudad de Buenos Aires y en la frontera sur, respectivamente, y habiéndolas estudiado en profundidad en investigaciones anteriores $^{14}$. El corpus documental que utilizamos está conformado por correspondencia oficial, actas y listados electorales, padrones de población y económicos, entre otras fuentes complementarias, que permiten realizar un examen holista del aspecto político, en estrecha vinculación con el social, cultural y económico ${ }^{15}$.

Nuestra hipótesis es que los procesos electorales en la campaña de Buenos Aires excedieron ampliamente al ámbito de las elites, incluyendo a sectores medios y subalternos, que si bien no participaron positivamente en la toma de decisiones oficiales y en la elección de un representante propio, contribuyeron a legitimar la construcción del republicanismo de forma activa. Esto implicó no sólo el apersonamiento real de los sufragantes el día del comicio y su intervención en un espacio público vital en la ritualidad cívica post-independiente, sino también el desarrollo de negociaciones y reciprocidades - sin duda asimétricas - entabladas con el gobierno provincial, como contrapartida a la legitimación del proceso político. Asimismo, en estas contraprestaciones e intercambios materiales y simbólicos, las autoridades locales de cada partido jugaron un rol central como intermediarias entre el Estado provincial y las sociedades vernáculas, canalizando recursos humanos como clientela electoral y generando consensos con los diferentes sectores que reglaban, aún en el marco del «unanimismo» ${ }^{16}$ rosista.

De tal forma, en primer lugar describiremos las características centrales que tuvo la estructuración y el funcionamiento del sistema electoral en la campaña de Buenos Aires desde la instauración de la ley de 1821 hasta el rosismo inclusive, para luego abordar con mayor detalle los rasgos que presentaron las prácticas electorales en los partidos de Quilmes y Azul-Tapalqué, considerando de manera confrontada sus perfiles socio-demográficos, económicos y su comportamiento electoral.

14 Santilli, 2008b. Lanteri, 2008b.

15 Joseph y Nugent (eds.), 1994.

16 El neologismo «unanimismo», «unanimista» hace referencia al sistema instaurado en la provincia de Buenos Aires bajo el gobierno de Juan Manuel de Rosas que permitía la presentación de una única lista electoral adicta al gobierno digitada por el gobernador. Es utilizado por la historiadora Marcela Ternavasio, 1999 y 2002. 


\section{LA ESTRUCTURACIÓN Y EL FUNCIONAMIENTO DEL SISTEMA ELECTORAL EN LA CAMPAÑA}

Si bien desde la instauración del estatuto de 1815 , e incluso antes, se extendió la representación política al ámbito rural de Buenos Aires, la implementación de la ley de 1821 constituyó un hito fundamental en la práctica política de los paisanos, y tanto el desarrollo regular anual de las elecciones para diputados de la Sala de Representantes como el respeto por la legalidad y la formalidad del acto eleccionario fue marcado como una continuidad entre las épocas rivadaviana y rosista ${ }^{17}$. Pese a que se ha planteado un cierto reflejo entre las facciones de las elites de la ciudad y el control de las elecciones en el partido de Areco, también se han registrado múltiples combinaciones de candidatos escogidos por los pobladores rurales en las elecciones de Quilmes en la década de $1820^{18}$. Estas variadas opciones entre aspirantes corresponden al período anterior al forjamiento del «unanimismo» rosista a partir de 1835 , y ya se ha destacado la importancia que tuvo la decisión de implementar o no una única lista de candidatos de representantes hacia el interior incluso del mismo federalismo porteño ${ }^{19}$.

Con todo, es dable destacar que a pesar de la continuidad en el desarrollo de las elecciones anuales en la campaña para refrendar la única opción de cada sección electoral, integrada sólo con adeptos al régimen rosista, las prácticas electorales y el control de la mesa escrutadora eran de vital importancia para el gobierno. Una misiva enviada por el edecán de Rosas al juez de paz de Monsalvo - de hecho, uno de los bastiones más resistentes al rosismo que fue luego sede del levantamiento de los Libres del Sur en 1839 - en 1836 - es decir, luego de forjado el «unanimismo»— refería de forma elocuente la relevancia del control de la mesa por las autoridades locales. En ese sentido le advertía que no debía dejarse sorprender por los «impíos unitarios» que lo pueden enredar y fraguar en el orden en las elecciones ${ }^{20}$.

Comprobamos entonces que pese a la vigencia del «unanimismo» en la campaña debía ser constantemente mantenido y resguardado, para lo cual el control de las mesas por parte de las autoridades locales era central. De hecho, la ley de 1821 estableció que los jueces de paz serían los presidentes de las

17 Ternavasio, 2002.

18 Garavaglia, 27 (Buenos Aires, 2005): 49-74. Santilli, 12 (Rosario, 2008a): 41-67.

19 Ternavasio, 1999: 119-141.

20 Carta de Manuel Corvalán al juez de paz de Monsalvo, Buenos Aires, 21 de noviembre de 1836, Archivo General de la Nación, Buenos Aires (AGN), Juzgado de Paz de Chascomús, 1828-52, X, 20-10-7. 
mesas electorales en la campaña, a diferencia de la ciudad, donde tenían carácter electivo por parte de la asamblea electoral que se constituía en cada comicio. Y vale aclarar que los jueces de paz en la campaña eran escogidos por el mismo gobernador de forma anual sobre una terna de vecinos que proponía el juez anterior ${ }^{21}$.

El acto electoral constituía un momento de gran carga simbólica en la ritualidad cívica independiente $\mathrm{y}$, como ha sido señalado, fue controlado por Rosas de forma directa, implementando una importante «maquinaria electoral» que comenzaba con la impresión de las boletas de cada sección electoral con el/los representantes elegidos por el gobierno, su distribución por tierra o por barco en el caso de los distritos más distantes como Patagones, los modelos de grillas electorales y las estrictas instrucciones a seguir por parte de las autoridades de cada partido y sección, hasta el retorno de los resultados obtenidos a Buenos Aires (a la Sala de Representantes con copia legalizada al gobernador) ${ }^{22}$.

Según decía el mismo Rosas a uno de sus edecanes en virtud de las elecciones de 1843:

«Remito á U. la carpeta del año pasado con todo lo relativo á las elecciones para que luego de recibir la presente se ocupe solo y puramente de este asunto; y que en su virtud mañana lunes por la mañana muy temprano haga dar principio á la impresión de las listas, y me las vaya mandando sin un solo momento de demora, procediendo U. en todo de conformidad á las órdenes que se registran en la misma carpeta para las listas del año anterior indicado, de 1842 (....) He mandado hoy el Decreto á la imprenta para que se publique en la Gaceta de mañana lunes cuatro; y también lo he mandado al Editor del Diario de la tarde para que asimismo sea publicado en el de mañana Lunes» ${ }^{23}$.

Rosas personalmente seguía los asuntos electorales para verificar su cumplimiento. En la misma nota le recrimina a su edecán no haber recibido las circulares para remitir a la campaña, donde se especificaban los datos de la próxima elección. Es que para él, el tiempo apremia y «todo debe quedar bien $\mathrm{y} \sin$ falta alguna» ${ }^{24}$.

21 Gelman, 21 (Buenos Aires, 2000): 7-31, autor que destaca que, sin embargo, la elección respondía en cierta medida al juego de las fuerzas internas de cada partido y al ascendiente del candidato entre sus vecinos.

22 Ternavasio, 2002.

23 Carta de Juan Manuel de Rosas, 3 de diciembre de 1843, AGN, Secretaría de Rosas, 1843 , X, 26-3-2A, folio 481 y vuelta. La grafía ha sido actualizada por los autores como en el resto de las citas.

24 Ibid. 
La emisión de las boletas electorales se hacía contemplando la cantidad de población de cada sección electoral, las que fueron ampliadas y modificadas luego de la crisis de 1839-40. Mientras el partido de Quilmes correspondía a la 4. ${ }^{a}$ sección de campaña, que incluía 2.000 boletas, Azul y Tapalqué estaban comprendidos en la 12. ${ }^{\text {a }}$, que de hecho era la más populosa de todas, generando la emisión de la significativa cantidad de 6.00025. Según refería uno de los edecanes de Rosas: «Como las de Dolores son en n. ${ }^{\circ}$ de 60(00); y hay que dar tiempo para secarse, contarse, y empaquetarse, esto demorará la remisión de las secciones distantes hasta mañana 5 de 10 á 11 de la mañana, en que irán las secciones 12,13 y $14 . . .{ }^{26}$ y así desde las secciones más distantes de la campaña hasta las de la ciudad. Y contestaba el mismo Rosas al otro día: «No es precisión que las listas de la sección 12. ${ }^{a}$ vengan todas juntas-Luego que estén listas mil de ellas pueden venir, y así seguir viniendo de dicha sección de a mil hasta el entero de las seis mil. De las demás secciones si pueden venir luego que esté el completo de cada una de ellas» ${ }^{27}$.

Junto a la impresión y reparto de las boletas, el gobierno provincial enviaba los modelos de padrón electoral y las instrucciones para las autoridades de cada partido, donde se aludía a la importancia de que participaran del comicio la mayor cantidad de personas posible en cada distrito. Una carta del edecán de Rosas al juez de paz de Azul en 1837 es elocuente al respecto. Según decía, había recibido órdenes expresas del gobernador acerca de la confección del padrón electoral:

«...lo que tiene U. que hacer es lo siguiente-En una lista nominal colocara los nombres y apellidos de todas las personas residentes en ese Fuerte, y su Campaña, siendo prevención que toda la milicia acantonada, o en servicio que se halle en dicho Fuerte o en su Campaña, debe votar, y que también deben votar todos los Individuos de tropa de línea siendo de sargento arriba-Para esto nada mas tiene U. que hacer que formar la lista, y recoger los votos con arreglo al siguiente formulario; y concluido lo cerrará, lo firmará, y lo hará firmar también con todos los que sepan hacerlo, y lo remitirá al Juez de Paz de Dolores con persona segura, y de toda capacidad, acomodándole la correspondencia bien amarrada de la cintura para que no la

25 A partir de la crisis de 1839-40 fueron creados nuevos partidos y secciones electorales en la campaña. Ternavasio sostiene que el cambio más trascendente estuvo radicado en la 12. ${ }^{a}$ sección, que de estar compuesta por tres juzgados civiles (Monsalvo, Tandil y Dolores), quedó constituida por catorce partidos: Monsalvo se dividió en Ajó, Tuyú, Mar Chiquita y Lobería Grande; Tandil en Tandil y Chapaleofú y Dolores en Tordillo, Pila y Dolores. Se crearon además los partidos de Vecino, Saladillo, Flores, Tapalqué y Azul. Ternavasio, 2002: 218-219. Prado y Rojas, 1871: 354-358.

26 Nota elevada a Juan Manuel de Rosas, Buenos Aires, 4 de diciembre de 1843, AGN, Secretaría de Rosas, 1843, X, 26-3-2A.

27 Nota de Juan Manuel de Rosas, Buenos Aires, 5 de diciembre de 1843, ibid. 
pierda, quien hecha la entrega, recogerá del Juez de Paz indicado el correspondiente recibo y regresará. Las adjuntas listas las remite á U. S.E porque son las que corresponden á la opinión del Exmo. Gobierno» ${ }^{28}$.

Y sumaba luego: «Como la presente correspondencia ha de llegar á manos de U. después del 22, dice S.E. que la votación puede por ello tener lugar el Domingo entrante veinte y nueve del corriente, y en su defecto por algún otro incidente casual, el miércoles primero de Noviembre, que es día de guarda, ó el domingo siguiente cinco del mismo. ${ }^{29}$

Vemos entonces que el accionar de las autoridades locales no se limitaba sólo al control de la mesa escrutadora el día del comicio, al empadronamiento de las personas «habilitadas» para votar y a la recolección de los votos, sino que comenzaba antes a partir de la confección y reparto de las boletas con la «opinión del gobierno», por parte de los jueces de paz, alcaldes y tenientes de cada cuartel. Además, se observa el apersonamiento real de los sufragantes el día del comicio y la ritualidad que implicaba el desarrollo del acto los días domingo o no laborables, posibilitando una mayor asistencia del electorado que un día laboral regular. Una misiva del juez de paz de Bahía Blanca - uno de los distritos más australes de la campaña- a Rosas en 1836 le refería que las elecciones no habían podido realizarse el día indicado en simultánea con el resto de la campaña, pero que se hicieron el domingo siguiente. De paso nos ilustra sobre la concurrencia, emisión y el resultado de la votación:

«... de lo que ha resultado Electo, por doscientos cuarenta y cinco votos unánimes de esta población, el ciudadano D. Julián Vivaz, por quien se ha sufragado según las listas del Exmo. Gobierno que V.E. se dignó remitirnos. La votación ha sido General sin faltar ninguno de los Ciudadanos que debían votar, Tanto en el vecindario, propietarios, jornaleros, rebajados de toda clase: como en la fuerza de Línea todos los que por la superior instrucción de V.E. debían votar» ${ }^{30}$.

28 Carta de Manuel Corvalán al Juez de Paz de Azul, Buenos Aires, 20 de octubre de 1837, AGN, Juzgado de Paz de Azul, 1835-40, X, 20-10-1.

${ }^{29}$ Ibid. En el caso de Azul y Tapalqué, hemos encontrado algunas escalas previas para la remisión de las boletas. Una carta del edecán de Rosas al juez de paz de Chascomús en 1838 le decía que había recibido orden del gobernador: «para decir á U. que el adjunto paquete para el Juez de Paz del Fuerte Azul debe U. dirigirlo á su rotulo sin demora luego que lo reciba, con persona de confianza quien debe recoger el correspondte. recibo de la entrega», Carta de Manuel Corvalán al juez de paz de Chascomús, Buenos Aires, 27 de noviembre de 1838, AGN, Juzgado de Paz de Azul, 1835-40, X, 20-10-1.

30 Carta de Martiniano Rodríguez a Juan Manuel de Rosas, Fuerte Argentino (Bahía Blanca), 4 de diciembre de 1836, AGN, Secretaría de Rosas, 1848, X, 25-5-1. Nótese el perfil del electorado referido por la autoridad. 
Hemos verificado, además, en base a la correspondencia y las actas de elecciones, que el voto emitido no sólo era de índole oral, sino que también podía remitirse escrito y refrendado con la firma - si era letrado - o una cruz - en caso contrario - del sufragante si eventualmente no podía apersonarse el día del comicio. La firma de las autoridades competentes y de la mayoría de los vecinos letrados también constituía un hecho significativo como forma de legitimar el acto electoral, además de la propia recolección de los votos.

Otra cuestión relevante a considerar es que la asamblea electoral se conformaba a las 9 de la mañana presidida siempre por el juez de paz del partido y se escogían a los otros tres miembros para dar comienzo al acto que concluía a las 16 hs. Estos integrantes generalmente eran seleccionados entre las autoridades y vecinos más importantes de cada distrito, como alcaldes, tenientes, jefes y oficiales de los regimientos de milicia o regulares, curas, médicos, etc., quienes usualmente se encuentran además encabezando las listas electorales. Luego de concluido el acto, se pasaba a realizar el escrutinio de los votos, los que a su vez eran remitidos al partido más antiguo de cada sección electoral ${ }^{31}$ - en el caso de Azul y Tapalqué a Pila - donde los presidentes de cada mesa de los distintos partidos se reunían a los dos días de finalizado el escrutinio local a realizar el recuento general de cada sección electoral, para luego remitirse definitivamente a Buenos Aires.

Habiendo descrito entonces los rasgos centrales del funcionamiento del sistema electoral en la campaña desde su instauración en 1821, a continuación examinaremos con mayor detalle nuestros casos de estudio de manera confrontada.

\section{DOS ESTRUCTURAS DE POBLAMIENTO DIFERENCIADAS}

Las investigaciones previas que hemos efectuado sobre los partidos de Quilmes y Azul-Tapalqué nos indican que se diferenciaban bastante desde diversos aspectos. En primer lugar, su ubicación geográfica. Mientras Quilmes fue incorporada al área de dominio de la civilización hispano-criolla en el siglo XVII, Azul y Tapalqué corresponden a las que denominamos producto de la expansión de la frontera de la tercera década del siglo XIX. Como se ve, doscientos años de diferencia entre la ocupación efectiva de ambas regiones.

Los primeros habitantes de lo que luego sería el partido de Quilmes fueron los aborígenes traídos desde los valles Calchaquíes como castigo por haber

31 Cada sección electoral incluía varios partidos contiguos, agrupaciones que persisten en la actualidad. 
mantenido una actitud de abierta oposición al dominio español y luego de su derrota total. Pero ya en el momento de la instalación de los desterrados, la tierra había sido apropiada aunque no ocupada; el dueño de las mismas donó la extensión equivalente a una suerte de estancia ${ }^{32}$ para la fundación de una reducción que los alojara, la que comenzó a funcionar en 1633. En ese entonces el territorio que nos ocupa formaba parte de Magdalena, que se extendía al sur de la ciudad hasta el río Salado. Hacia fines del siglo XVIII, cuando ya la reducción era simplemente una institución formal con habitantes que no descendían en su gran mayoría de los originales, se fundó el partido de Quilmes, que abarcaba desde el Riachuelo, el límite sur de la ciudad, hasta el arroyo del Gato, en las cercanías de la actual ciudad de La Plata. La región se había ido poblando al compás de las migraciones del interior del virreinato del Río de la Plata, más allá del territorio asignado a la reducción, al punto tal que el partido contaba con 1.615 habitantes según el censo de 1815. En 1812 la reducción había sido disuelta por un decreto del Primer Triunvirato y su territorio declarado de propiedad del Estado, aunque los indígenas, ya sólo 216 en el mejor de los recuentos, permanecían en tal parcela ${ }^{33}$. A partir de ese registro de 1815 el crecimiento demográfico del partido fue uno de los más altos de la campaña, llegando en 1838 a contar con 4.288 habitantes, con un incremento del $4,34 \%$ anual acumulado, en razón del intenso proceso migratorio que experimentó 34 .

La conformación y posterior evolución demográfica de Azul y Tapalqué fueron totalmente diferentes. En 1829, el gobierno de Viamonte dispuso la cesión de tierras fiscales a los pobladores y familias que quisieran establecerse en el Azul y en los campos fronterizos del Estado, a cambio del poblamiento efectivo, la puesta en producción y la defensa territorial regional por parte de estos vecinos-milicianos, que a la vez de poblar la frontera la resguardarían con sus propias armas y caballos. Con todo, la entrega efectiva de las «suertes de estancia» a los colonos fue reactivada por Rosas recién a partir de 1832, de forma paralela a la ubicación de las tribus de «indios amigos» más fieles al gobierno en el partido contiguo de Tapalqué — establecido como cantón militar en 1831 - y a su campaña militar al río Colorado de 1833-34. El partido de Azul fue establecido oficialmente en 1835, con la designación de su primer juez de paz, dependiendo antes de la jurisdicción de Chascomús, aunque sus límites fueron modificados en 1839. Por su parte, Tapalqué dependió administrativamente de Azul hasta 1846, en que fue designado su primer juez de paz.

32 Una extensión de 1/2 legua por 1,5 leguas, equivalente a 2.025 hectáreas.

33 Santilli, 22 (Tandil, 2007): 13-40.

34 Un relato del desarrollo histórico-demográfico del partido en Santilli, 2008b: cap. 1. 
Si bien ya existían asentamientos poblacionales previos en el marco del usufructo enfitéutico en la década de 1820, que coexistieron eventualmente con las tolderías del cacique Venancio, el poblamiento de la región se vio incrementado con creces a partir de estas donaciones de terrenos públicos, por parte de pobladores y familias provenientes de Buenos Aires, de otros lugares de la campaña rioplatense o extranjeros. La población estimada por el padrón de Azul en 1838 era de 2.835, mientras el censo provincial de 1854 estableció un total de 5.912 personas, con una tasa de crecimiento porcentual anual del $4,7 \% \%^{35}$. En esa fecha, se registró la notable cifra de 6.000 «indios» en Tapalqué, sobre un total general de 6.515 individuos, cuya territorialidad regional y magnitud demográfica fueron relevantes hasta su expulsión finisecular ${ }^{36}$.

En cuanto al perfil productivo, también había diferencias. En ello influyó de manera fundamental la distancia con la ciudad de Buenos Aires. Mientras Quilmes, debido a la cercanía con el gran mercado consumidor citadino, se iba especializando en los cultivos de granos $\mathrm{y}$, en segunda instancia, en forrajes para los animales de transporte, Azul dedicaba sus mayores esfuerzos a la cría de ganado para el comercio atlántico de cueros. Contaba en 1839 con 150.000 cabezas de ganado vacuno y 60.000 de ovino, ubicándose como el cuarto de los partidos en cuanto a patrimonio en ese rubro; en cambio Quilmes tenía su mayor riqueza en la tierra, valorizada fundamentalmente por su papel como bien esencial para la actividad agrícola que ya describimos. Pero también en su zona aledaña a la ciudad, sólo separada por el Riachuelo, estaban radicados los saladeros característicos del período, y las barracas que servían de depósito de cueros para la exportación. También una parte nada despreciable de sus pobladores se dedicaban a la ganadería ovina, convirtiéndose en una avanzada de los tiempos por venir. Ello había generado en ambos partidos una distribución de la riqueza no tan desigual como en el conjunto de la campaña de Buenos Aires; ambos muestran un coeficiente Gini por debajo del promedio de toda la provincia $^{37}$. Tal vez la mayor diferencia entre ambos partidos tenía que ver con la escala de los productores; mientras los del partido cercano trabajaban en pequeñas parcelas, con un rendimiento considerable en razón de ese tamaño, los del sur estaban asentados en extensiones mucho mayores, por más que

35 Cabe destacar que en trabajos anteriores hemos considerado un total de 3.106 personas en Azul en 1838 y una tasa de crecimiento porcentual anual de 4,1\% durante el lapso, porque hemos agregado a los cabezas de unidad censal a la población general. Lanteri, 2008b y otros.

36 Infesta, 1994: 269-286. Lanteri, 62/2 (Sevilla, 2005): 251-283; 14 (La Plata, 2007). Ratto, LXIII/227 (Madrid, 2003): 191-222. Pedrotta, 2005. Lanteri y Pedrotta (Mendoza, 2009).

37 Gelman y Santilli, 2006: cap. 1. 
las «suertes de estancia» constituían predios reducidos frente a otras grandes estancias de la región, con un rendimiento menor por medida de superficie. Sin embargo, la distribución era mejor en el sur, ya que el $75 \%$ de los jefes de familia poseía algún bien, mientras que en Quilmes la proporción, si bien era alta, se reducía a la mitad.

Desde el punto de vista institucional las diferencias parecen tener que ver con su antigüedad y con razones geográficas y políticas. Mientras Quilmes conoció diversos tipos de autoridades o de estructuras que gobernaban su territorio, como curas párrocos, jefes de la guarnición militar, caciques, cabildo indígena, alcaldes de hermandad, hasta concluir en los jueces de paz, la colonización oficial de Azul fue impulsada por el gobierno rosista mediante las donaciones de tierras, naciendo bajo la égida de comandantes militares vinculados a Rosas, como en Tapalqué, y los jueces de paz, en la década de 1830.

Desde el punto de vista social, las jerarquías de la colonia se mantuvieron por mucho tiempo en Quilmes, aunque para el tiempo que nos ocupa, tales jerarquías se habían ido disolviendo en virtud del intenso proceso migratorio y por la pérdida de importancia de las antiguas prerrogativas basadas en el status. Esta situación no se repetía por supuesto en Azul ni en Tapalqué, ya que sus nacimientos datan de la época donde esos privilegios casi no existían ${ }^{38}$.

Por último, en las actitudes políticas, Azul era considerado un reducto federal por excelencia, al punto que fue el asentamiento de las fuerzas de Prudencio Rosas (hermano del gobernador), que lograron derrotar la sublevación de los Libres del Sur en 1839, y permaneció fiel al gobierno hasta su caída en 1852, al igual que Tapalqué, donde tenían sede las tribus más numerosas y adeptas de toda la provincia. Si luego de derrotada dicha sublevación y superada la crisis del bloqueo francés, el régimen embargó a los terratenientes que intervinieron en tales hechos, y los partidos vecinos a Azul se ubicaron entre los más afectados, los pobladores de Azul casi no sufrieron la ira del poder; sólo 14 propietarios fueron embargados. No pasó lo mismo en Quilmes, que fue uno de los tres partidos con mayor cantidad de embargados, y hasta fue fusilado un juez de paz; un verdadero «nido de unitarios»"

Luego de haber marcado estas diferencias y similitudes, vamos al nudo de nuestra cuestión que es la comparación de los comportamientos electorales.

38 Sobre las jerarquías sociales en Quilmes ver Santilli, 2008b. Sobre Azul-Tapalqué, Lanteri, 2008b.

39 Gelman y Schroeder, 83:3 (Duke, 2003): 487-520. 


\section{COMPORTAMIENTOS ELECTORALES}

Hay que señalar, en principio, que los inicios electorales no fueron paralelos; mientras Quilmes inaugura el nuevo sistema electoral de 1821, junto con el resto de los partidos de la campaña, Azul nace a esas lides diez años después, con el sistema ya funcionando. En ese sentido, si el régimen electoral de competencia entre elites concluye con la década de $1820^{40}$, Azul no conoció esa época. En efecto, en Quilmes se votó desde el primer año de vigencia de la ley de sufragio de 1821, aunque no nos han llegado las actas de tales primeras elecciones. Es más, durante los primeros años hubo realmente competencia entre diferentes candidatos, aunque la lista oficial ganaba siempre; luego de 1830, esa posibilidad despareció; se votaba únicamente la lista «aconsejada» por el gobierno, como vimos en el apartado 2. En Azul, por supuesto, esto no ocurrió; siempre se votó la lista única postulada por el gobierno rosista.

Veamos nuestros puntos de referencia. Para Quilmes contamos con las actas de elecciones de 1824, 1825, 1830, 1837, 1838 y 1839, es decir seis elecciones. De Azul, en algunos casos combinado con Tapalqué, contamos con siete actas consecutivas entre 1837 y 1844, con la excepción de 1839.

Lo primero a destacar en el caso de Quilmes es el incremento constante de la cantidad de votantes, con una leve merma en 1838, hasta estabilizarse en alrededor del $10 \%$ de la población. El siguiente cuadro nos lo muestra.

Cuadro 1. Porcentaje de participación electoral en Quilmes SOBRE POBLACIÓN ESTIMADA

\begin{tabular}{|l|c|c|c|c|c|c|}
\hline & 1824 & 1825 & 1830 & 1837 & 1838 & 1839 \\
\hline Población & 2.367 & 2.469 & 3.053 & 4.110 & 4.288 & 4.474 \\
Votantes & 83 & 96 & 208 & 426 & 390 & 493 \\
\% de participación & 3,5 & 3,9 & 6,8 & 10,4 & 9,1 & 11,0 \\
\hline
\end{tabular}

A los efectos de poder comparar con Azul-Tapalqué y con otros partidos de la campaña, hemos establecido la relación con el total de habitantes, a pesar de que, como vimos, los habilitados para votar eran sólo los varones mayores de 20 años. En los censos de la década de 1830 sólo se consignaba el nombre del jefe de familia y la cantidad de personas que habitaban cada unidad censal de forma agregada, según variables étnicas y militares. Por tal motivo

40 Ternavasio, 2002. 
no se puede establecer el sexo y la edad de los habitantes registrados, condición indispensable para establecer la población habilitada a votar. Pero en el caso de Quilmes pudimos hacer esa cuenta, que muestra que sufragaba el $40 \%$ de los posibles votantes, cifra que nos parece satisfactoria ${ }^{41}$. Asimismo, es notorio el incremento absoluto de año en año de los votantes; más que se duplicó en 1830 con respecto a la cifra de cinco años antes, y volvió a doblarse en 1837 , con respecto a 1830 . Hay aquí un esfuerzo evidente por captar votantes, en consonancia con lo expuesto en el apartado anterior, cuyas razones, entre otras, se pueden presumir: la necesidad de legitimación del régimen y la asunción de que el único modo para ello era el sufragio.

Veamos qué sucedía en Azul y Tapalqué.

Cuadro 2. Porcentaje de participación electoral en Azul y Tapalqué SOBRE POBLACIÓN ESTIMADA ${ }^{42}$

\begin{tabular}{|l|c|c|c|c|c|c|c|}
\hline & $1837^{1}$ & 1838 & 1840 & 1841 & 1842 & 1843 & 1844 \\
\hline Población & 3.502 & 2.835 & 3.108 & 3.254 & 3.407 & 3.567 & 3.735 \\
Votantes & 800 & 1.037 & 394 & 427 & 854 & 701 & 691 \\
\% de participación & 22,8 & 36,6 & 12,7 & 13,1 & 25,1 & 19,7 & 18,5 \\
\hline
\end{tabular}

1 Incluye Tandil.

Como se puede apreciar, a diferencia de Quilmes, donde notamos una tendencia al crecimiento, el porcentaje de participación era más variable, con picos y depresiones. En los momentos críticos del régimen, $1838^{43}$, se nota el

41 La población se estima teniendo en cuenta el crecimiento que hemos consignado más arriba, de 4,34\% anual. Las correlaciones originales con los habilitados a votar, en Santilli, 12 (Rosario, 2008a): 51-53.

42 La estimación de la población se realizó sobre los datos censales de Azul, por carecer Tapalqué de registros precisos en 1838. La población estimada de Azul se efectuó partiendo del censo de ese año (2.835 habitantes) y concluyendo en el de 1854 (5.912), esta última cifra según lo publicado por Maeder, 1969: 35. La tasa de crecimiento calculada es de 4.7\% anual, mayor que el promedio del conjunto de la campaña, que fue de 4.29, y de Quilmes, según consignamos. La tasa de la campaña extraída de Moreno y Mateo, 12 (Tandil, 1997): 41. La cifra de habitantes de Azul en 1838 (2.835) difiere de la que hemos usado en otra publicación (2.265) para estudiar la distribución de la riqueza en el partido, en razón de que en aquella oportunidad decidimos no incluir los soldados-milicianos del fuerte, denominado en el censo «en el cuartel de esta fortaleza». Ver Gelman y Santilli, 2006: 82. Recordemos asimismo la salvedad mencionada en la nota 35 sobre las cifras de población y la tasa de crecimiento de Azul.

43 Durante el período 1838-40 se sucedieron varios episodios especialmente críticos para la estabilidad del gobierno rosista, como la guerra con la confederación peruana-boliviana de 
guarismo más alto, para luego decaer fuertemente dos años después. Otra alza importante se da en 1842, en paralelo con la tendencia general observada en la campaña, pero luego nuevamente baja para estabilizarse en algo menos del $20 \%$; aunque este dato no es menor, pues refiere a la legitimación otorgada al régimen por el vecindario luego de la crisis del sistema federal de 1838-40. De todos modos, trazando un paralelo con nuestro otro partido, la participación de la población en la zona fronteriza era mucho mayor. En los años para los cuales tenemos información de los dos distritos, Azul-Tapalqué duplicaba el porcentaje de votantes de Quilmes en 1837 y lo cuadruplicaba en 1838. Incluso las cifras absolutas rondaban el doble en el sur en ambos años. Se ha podido comprobar incluso que Azul-Tapalqué presentaba índices bastante más altos de participación electoral con respecto de otros partidos de la misma frontera austral en 1838 y 1842, mostrando claramente la filiación federal de la población frente a otros que incluso fueron el epicentro de levantamientos contrarios al régimen, como la rebelión de los hacendados de 1839-4044.

Ahora bien, según ha sido demostrado, la proporción de habilitados para votar en Quilmes, es decir, los varones libres mayores de 20 años, era del 26\% de la población ${ }^{45}$. En el caso de Azul, si aplicáramos esa misma escala, tendríamos que en 1837 votó el $88 \%$ de los habilitados para ello, en 1840 tendríamos la menor proporción, $49 \%$, y en 1843-44 superaría el 70\%, porcentajes lo suficientemente elevados si los comparamos incluso con las actuales elecciones, con voto secreto, obligatorio y padrón automático. Sin embargo, una sorpresa mayor es la relación en la elección de 1838, donde la cantidad de votantes superaría en un $40 \%$ a los vecinos habilitados. Aún suponiendo que esa proporción de habilitados fuera mayor al $26 \%$, porque la relación de masculinidad en Azul era mayor y la población más adulta en razón de la presencia de los soldados-milicianos del fuerte, es difícil que pueda revertirse esa tasa del $40 \%$ de exceso ${ }^{46}$. Es entonces evidente que, por lo menos en 1838 , votaron en Azul ciudadanos que excedieron a los vecinos formalmente habilitados para hacerlo, incluyendo a dependientes y otros sectores económicos y socio-étnicos, como indios, soldados regulares y milicianos, etc., según ha sido demostrado asimismo para otros años ${ }^{47}$.

1837-39, la revolución de los «Libres del Sur» en octubre-noviembre de 1839, el levantamiento de Lavalle en agosto de 1840 y el bloqueo francés al puerto de Buenos Aires, entre otros.

44 Lanteri, 12 (Rosario, 2008a): 15-40.

45 Santilli, 12 (Rosario, 2008a): cuadro 2, nota 40, pág. 52.

46 La relación de masculinidad en Azul en oportunidad del censo de 1869 era de 130,2 y en la cercana Dolores en 1838 de 122. Lanteri, 12 (Rosario, 2008a): 24-25.

47 Ibid. En el partido de Areco en 1838, se demostró que sufragaban las 3/4 partes de la población habilitada. Ver Garavaglia, 27 (Buenos Aires, 2005): 61. 
Esto también pasaba en Quilmes. Si hacemos una comparación entre los nombres de los votantes y los registros censales y de otro tipo, como los archivos parroquiales o los registros impositivos, nos encontramos con una alta proporción de nombres que no fueron registrados en ninguno de ellos, más allá de las actas electorales. Esta proporción varía desde un $23 \%$ en 1824, a un $40 \%$ en 1839 , aunque podemos decir que la relación se estabilizó en algo más del $30 \%$ a partir de $1830^{48}$.

Es decir, que en ambos casos y por diversos métodos, llegamos a la conclusión que no todas las personas que votaron en cada partido que estamos analizando eran vecinos arraigados en los mismos, evidenciando la amplitud del mercado electoral. Se puede suponer entonces que se trataba de un elenco rotativo de personas adictas al régimen que se desplazaban de partido en partido para emitir su voto, máxime teniendo en cuenta que sólo el juez de paz certificaba su vecindad y su capacidad para votar. Dado que el sistema se legitimaba por el voto popular y que esta condición, establecida por la ley de 1821, no fue modificada nunca por el rosismo, la posibilidad de movilizar votantes de partido en partido, burlando la ley podría estar sustentada en esa necesidad. Del mismo modo, no sólo el rosismo habría apelado a los votantes «volantes», ya que registros de personas desconocidas por nosotros encontramos en todas las elecciones analizadas en Quilmes, tanto antes como después de 1830, es decir, tanto bajo la competencia entre elites como bajo el «unanimismo». En 1825 era de un $38,5 \%$, y en 1830 , del $31,7 \%$ de los sufragantes; mientras que en 1838 era de 32,3\% y en 1839 del 39,6\%. En Azul-Tapalqué también se han registrado nombres poco conocidos, aunque la constante es una gran repetición de apellidos entre las listas de sufragantes, lo que refiere a la continuidad en el asentamiento durante el lapso, e incluso posteriormente, que se condice con los patrones hallados sobre la estructura poblacional y de tenencia de la tierra. Sin duda la manipulación de votantes y padrones pudo haber ocurrido; pero es una parte de la explicación, ya que conocemos de la alta movilidad de la población en esa época, situación que también se daba en la frontera sur.

Ahora bien, si suponemos que el sistema rosista era omnímodo y coercitivo, que basaba todo su poder en la fuerza, ello habría bastado para hacer que la población de cada distrito fuera obligada a emitir su voto. Es decir, que la población estable del partido se habría visto obligada a participar en los comicios por diversas razones, entre las que no sería menor el clientelismo. En efecto, tal como una visión historiográfica propone, el sistema establecido por Rosas desde el Estado y desde su posición de «patrón de estancias», estaba basado en

48 Santilli, 12 (Rosario, 2008a): cuadro 4, pág. 56. 
el clientelismo y la coerción, sistema que se extendía a la «clase terrateniente» en general, es decir, a los otros patrones de estancia ${ }^{49}$, régimen del que por supuesto formaba parte la componenda electoral. Si fuera así, consideramos que los porcentajes de votantes deberían ser mucho mayores, por lo menos en el caso de Quilmes, ya que si semejante fortaleza sólo alcanzaba para juntar el $11 \%$ de la población en el mejor de los casos, o el 25\% de los teóricamente habilitados para votar, evidentemente el sistema fracasaba. Podría suponerse que en un reducto como Quilmes, «nido de unitarios» según la expresión de la Mazorca, esta coerción era muy difícil de llevar a cabo. Otra situación debería darse entonces en Azul, un partido formado bajo el rosismo, a partir de la donación oficial de tierras fiscales y con una importante guarnición de milicia para cuidar la frontera. Se podría encontrar en ese caso la máxima expresión del clientelismo y la coerción. Veamos si así era.

En junio de 1838 había acantonada en Azul una fuerza miliciana de 655 hombres, entre caballería, infantería y unos ochenta milicianos pasivos. Un año antes había 660 milicianos, según una investigación de Silvia Ratto; en 1845 se contaron 591 hombres $^{50}$. Es decir, que en todo el período en estudio habría un promedio de 600 «ciudadanos en armas» en Azul. ¿Qué fuerza más indicada que esa para ejercer la coerción y hacer concurrir a sus componentes en procesión a la mesa electoral? Sin embargo, el cotejo con las elecciones de diciembre de 1842, cuando la participación en el acto electoral había sido del $25 \%$ de los habitantes del partido, nos permite vislumbrar algunas tendencias. Una revisión de las actas arrojó que en promedio en todas las fuerzas milicianas de los regimientos $n$. ${ }^{\text {ss }} 5$ y 6 de campaña votó el $42 \%$ de sus componentes. Es decir, que sólo cuatro de cada diez milicianos se acercaron a la mesa electoral presidida por el juez de paz y compuesta por el cura párroco y los oficiales de los regimientos de milicia, es decir, bajo la atenta mirada de los jefes de los mismos cuerpos. Aquí podemos descontar entonces la suposición de coerción, ya que la misma no se imponía ni sobre la propia tropa de milicianos; tampoco podríamos hablar del caso típico de clientelismo si las autoridades militares no consiguen movilizar más de cuatro de cada diez milicianos. Por último, y visto desde la otra arista del clientelismo ${ }^{51}$, había seis soldados de cada diez que no

49 La más común de esas interpretaciones es la de Lynch, 1986.

50 Las cifras y citas en Lanteri, 12 (Rosario, 2008a): 32-33. También los originales del censo de 1838 indican que había 603 hombres en «el cuartel de esta fortaleza», AGN, Padrón de Azul, 1838, X, 25-6-2.

51 Para que exista clientelismo, es necesario un patrón y un cliente, es decir, un par de componentes; en definitiva, no sólo debe tenerse en cuenta al protector sino también la voluntad o la necesidad del protegido de someterse a ella. Trotta, 2003. 
consideraban que podían obtener algún rédito desde la participación electoral. Recordemos además que recién a partir de la creación de las Guardias Nacionales en la década de 1850 fue obligatorio estar enrolado en ellas para poder acceder formalmente al sufragio, cuestión que no pasaba en el lapso estudiado por nosotros, donde los electores votaron en calidad de vecinos más que de milicianos $^{52}$.

Sin embargo, entre los soldados y oficiales de las fuerzas regulares no pasaba lo mismo; es evidente que entre ellos sí podemos hablar de clientelismo, por lo menos, más justificable si entendemos que ellos percibían un sueldo regular del Estado. El porcentaje era muchísimo más alto, superaba el $90 \%{ }^{53}$.

Así y todo, la cantidad de sufragantes correspondientes a ambos tipos de organización armada fue de 429 personas; y si observamos que el total de votantes de ese año ascendía a 854 , la proporción de votantes militar-milicianos ergo era del $50 \%$. Otra cuenta que puede hacerse es cuánto incidían estas fuerzas en el total de la población; si descontamos los militares del total de la población y a su vez descontamos del total de votantes los sufragantes no reclutados, el porcentaje de votantes civiles sobre la población civil llegaba al 16\%, guarismo que sigue siendo elevado con respecto a Quilmes, pero que no parece ya desentonar tanto. En otras palabras, y según lo expuesto hasta aquí, lo que estamos tratando de demostrar mediante nuestro análisis es la escasa incidencia, si es que la tuvo, de la coerción y el clientelismo de índole privado en la composición de los votantes ${ }^{54}$.

Pero queda en pie aún la cuestión de los sufragantes que no formaban parte de la población estable registrada en Quilmes, lo que también sucedió eventualmente en Azul. En ese sentido, nuestra presunción se basa en la gran movilidad. La infinidad de transeúntes de toda naturaleza que se desplazaban por la campaña lo abona. La principal razón de tal tráfico es por cierto las necesidades temporales de mano de obra, por el lado de la demanda, y la todavía no dificultosa posibilidad de establecerse en forma independiente como pequeño productor en la campaña, desde el lado de la oferta. Esto podía generar una cantidad importante de personas que en el momento de la elección se encon-

52 Sábato, 2005.

$53 \mathrm{Y}$ ello a pesar de que la recomendación del poderoso gobernador era que voten todos los soldados, milicianos y pobladores, sin excepción, según vimos en el apartado 2.

54 Vale señalar que no hemos encontrado una correspondencia directa entre los miembros de las mesas electorales y sus actividades particulares, ya sea como padrinos de matrimonios en Azul-Tapalqué u otro tipo de relación entre patrones y dependientes en Quilmes, cuestiones que matizarían - por lo menos en estos aspectos- la incidencia del clientelismo privado en la movilización electoral. 
traban de paso, de manera tal que no dejaban registro perdurable en el partido, como por ejemplo jornaleros temporarios que una vez concluido su contrato volvían a su lugar de origen o donde tenían su residencia ${ }^{55}$. De alguna manera, estas personas eran captadas por el proceso eleccionario, combinándose la necesidad de votantes por un lado, con la de insertarse de algún modo en la comunidad del recién llegado. Es decir, una especie de negociación entre dos partes necesitadas una de otra, una especie de reciprocidad, cuya asimetría ya ha sido analizada en otra parte ${ }^{56}$.

Otra comprobación es la de la repetición de los sufragantes; es decir, si a través de los años se puede percibir que los votantes eran los mismos. Estamos hablando de un momento donde el voto no era obligatorio y los padrones previos no existían. Los votantes voluntarios debían inscribirse especialmente en cada ocasión y luego emitir su voto en voz alta ante los integrantes de las mesas electorales que en general eran las autoridades civiles y militares del partido. Puede, por tanto, ser aleatorio que encontremos repeticiones de votantes entre una elección y otra. Aquel que se registró y votó en 1837, por las muchas razones que van desde un acto volitivo hasta la presunción de que se hallaba compelido a hacerlo, puede que un año, dos o tres después decida no emitir su voto, o que directamente lo haga en otra jurisdicción, debido a la movilidad. $\mathrm{O}$, no hay por qué negarlo, deje de ser necesario para el sistema que tal ciudadano emita su voto, y no se lo convoque más o menos compulsivamente, entre otras cuestiones. Pero si hoy en día nos resulta imposible pensar en Argenti$\mathrm{na}^{57}$ en un porcentaje alto de personas que no votan en varias elecciones, para esa época, con las limitaciones mencionadas, sería impensable encontrar grandes repeticiones. Asimismo, el hecho de registrar siempre el mismo elenco abonaría la tesis de la movilización pura y simple de clientes u obligados a votar por algún mecanismo. Pero veamos los datos que poseemos.

En Quilmes hemos analizado seis elecciones, aunque separadas por quince años, lo que implica que tal lapso está incidiendo en la baja en las repeticiones. En efecto, en semejante período temporal muchos pudieron mudarse, envejecer y morir; y muchos otros incorporarse cada año a la población, así como nacer y crecer. Por ello, nuestra expectativa de repeticiones no era muy grande

55 Recordemos, como ya mencionamos, que muchos podían encontrarse censados de forma agregada y no nominal como mano de obra de los establecimientos productivos en los padrones de 1836 y 1838 .

56 Lanteri, 2008b: cap. 3. Santilli, 2008b: cap. 7.

57 En Argentina, el voto es obligatorio para todo ciudadano o ciudadana mayor de 18 años y sólo se los exime de votar a los ancianos y a los que están momentáneamente a más de 500 $\mathrm{km}$ de su residencia. 
y por cierto se confirmó ${ }^{58}$. Si consideramos que el acto de votar era volitivo y totalmente libre, resultaría desconcertante pensar en cuánto les costaba a las autoridades que los pobladores incorporen la práctica electoral entre sus costumbres, por constituir parte de la nueva cultura política del período independiente.

Sin embargo, parece que se acrecentaba anualmente el porcentaje de votantes que ya lo habían hecho en otra oportunidad. La escalada en ese sentido es notoria. En 1825 sólo el 6\% de los votantes lo había hecho el año anterior; pero en 1830 , el $12,5 \%$ ya había votado en las dos elecciones previas que contabilizamos. A partir de 1837, en el apogeo del rosismo en el poder, la subida es progresiva; ese año el porcentaje fue del 21,6, en 1838 del 56,7, llegando en 1839 al 85; es decir, de los 493 sufragantes, 419 ya habían concurrido con anterioridad a la mesa electoral, y 10 de ellos lo venían haciendo desde 1824, aunque ninguno por más de tres veces. Es decir, que por las razones que podamos suponer, pero sobre las que hablaremos más abajo, aquéllos que comenzaron a participar en las elecciones desde la instauración de la ley de 1821, en una alta proporción lo siguieron haciendo posteriormente.

En el caso de Azul y Tapalqué tenemos una elección más, pero como se trata de actos casi consecutivos durante el lapso de 1837-44, la incidencia de los decesos y de las incorporaciones por edad es menor. También la movilidad, pero de todos modos consideramos que siguió siendo alta, ya que la temporalidad y el tipo de economía permitía mudanzas de un año para otro. Pero en algunos casos las listas nominativas de los votantes no están completas, por lo que no pudo hacerse el mismo desarrollo analítico que en Quilmes. De todos modos, pudimos establecer que, si bien ese aumento que notábamos para el partido de cercanías no se vislumbra en la frontera, el porcentaje de reiteración de los votantes estaba en el orden del $50 \%$ y más aún en algunos años. En 1840 , por ejemplo, el $54,8 \%$ ya había votado en 1838 ; en tanto en 1844 el $59,2 \%$ había participado en la elección de 1843, mostrando la importante legitimación electoral al régimen por parte de este «vecindario federal», incluso luego de la crítica coyuntura de 1839-40.

En definitiva, no parecen vislumbrarse acciones que compelan a votar a la población, más allá de un posible círculo estrecho de apoyos incondicionales y de conveniencias mutuas.

58 De modo que nadie llegó a estar en las seis elecciones citadas, sólo cuatro en cinco, 27 en cuatro, 109 en tres y, por último, 235 en dos. En total, el 32\% de la totalidad de los votantes en Quilmes lo hicieron más de una vez, pero lo que más abundaba era la presencia en dos elecciones. 


\section{CONCLUSIONES}

El objetivo de este trabajo fue realizar un primer análisis comparativo de las prácticas electorales en la campaña de Buenos Aires, en el marco más general del estudio de la construcción del orden estatal y republicano en el mundo rural independiente en vinculación con el accionar social. El resultado del estudio de las elecciones en Quilmes y en Azul-Tapalqué muestra en algún punto diferencias entre los partidos, pero en el fondo se percibe que uno de los objetivos de los gobiernos independientes, tanto en la época de Rivadavia como en la de Rosas, que era legitimarse a través del voto, se pudo lograr. En buena medida el intento se ve coronado con el constante incremento de la participación de los paisanos en las elecciones, más considerando que constituyó una nueva experiencia política para los actores coetáneos.

Como hemos podido explicar, descartamos una coerción absoluta para lograr la concurrencia a la mesa electoral, pese a la composición de las mismas. Si bien se puede presumir que existió en algunos momentos, nos parece más razonable interpretar el proceso a partir del convencimiento y/o la negociación. Ya ha sido descrito por otros investigadores cómo se logra construir una opción política a favor de los paisanos a través de la figura de Rosas ${ }^{59}$. Asimismo, las dificultades para disciplinar la propia mano de obra en las estancias del gobernador indican que esos obstáculos debían ser aún mayores para los patrones de estancia que no contaban con ese poder ${ }^{60}$. Además son de destacar los inconvenientes con que chocaba el mismo Estado y los nombrados terratenientes para lograr dominar una población levantisca y astuta, que lograba negociar a veces en un pie de igualdad ${ }^{61}$. De modo que nada nos autoriza a pensar que en la cuestión de las elecciones otro debería ser el resultado.

Podemos especular que en un marco de discurso único o por lo menos dominante - el federal rosista - se fue imponiendo un cierto grado de temor a diferenciarse. Máxime en la medida que se fue generalizando la imagen de lo que les pasaba a los que persistían en la diferenciación, ya avanzada la década de 1830 (como embargos, confiscaciones, persecuciones, el exilio, o la muerte misma). Tal vez un puntapié inicial para el control del ámbito rural desde el rosismo fueron las clasificaciones de los habitantes por su color político que hicieron los jueces de paz de cada partido en 1830-3162. Sobre todo porque

59 Fradkin, 2006.

60 Gelman, 1998: 223-240.

61 Salvatore, 5 (Buenos Aires, 1992): 25-47.

62 Estas clasificaciones se pueden consultar en AGN, X, 26-6-5a y b. Un estudio de dichas fuentes en Gelman, 19 (Tandil, 2004a): 359-390. 
ello permitía que las enemistades personales o locales, a la vez que diferencias sociales, o clasistas diríamos hoy, se manifestaran bajo formas políticas. Luego vinieron los embargos y confiscaciones a los considerados unitarios que apoyaron el bloqueo francés y la invasión de Lavalle en 1839-40, que fueron muy importantes en la campaña y que, si bien afectaron mayormente a los grandes propietarios, también podían llegar a los menos pudientes ${ }^{63}$.

Pero si bien esta construcción es válida y posible y podría afectar a un porcentaje de los pobladores de la campaña, creemos que fue más importante la construcción del rosismo como expresión política de un determinado programa surgido de las clases populares. Tal proyecto se fue construyendo durante la década de 1820 y expresaba las aspiraciones de pequeños propietarios, jornaleros, migrantes, esclavos o libertos, etc., que pensaban que ante el avance de los sectores que querían delimitar sus derechos consuetudinarios debían rebelarse. A ello debe agregarse el intenso reclutamiento que generó la guerra con el Brasil y el profundo deterioro en los sueldos de los jornaleros que acarreó el proceso inflacionario de 1826; todo ello fue el caldo de cultivo para que se produjeran actos de bandolerismo que lentamente fueron adquiriendo un cierto carácter político. Y que explotó en el verano de 1829, una vez fusilado Dorrego, adquiriendo un definitivo tinte federal y rosista, movimiento del cual Rosas supo obtener el rédito suficiente para llegar al poder. Muy consciente de tal movilización política, se propuso dominarlo y como tal consiguió el apoyo a regañadientes de la elite porteña ${ }^{64}$. La propuesta de Rosas era la de restaurar el orden que permitiera a la elite económica hacer negocios en plena «expansión ganadera». Es decir, utilizar su ascendiente sobre los pobladores pobres para contenerlos mediante algunas concesiones que no comprometieran la hegemonía económica de los más ricos. Evidentemente, esa propuesta convenció a los poderosos, pero también a los más pobres, que veían en él al restaurador de los antiguos derechos consuetudinarios conculcados por las elites liberales anteriores. Este carácter de doble restaurador, este esquema, le permitió a Rosas no sólo llegar al poder sino además mantenerse en él, o ser su árbitro, hasta la gran crisis del sistema federal en 1839-40 —e incluso luego según la evidencia encontrada en la frontera-.

Y fueron las elecciones el modo en que el sistema rosista logró encontrar la legitimidad necesaria para perpetuarse, más allá del trance al que hacíamos referencia, es decir, la gran crisis. La meticulosidad con que se cumplían las normas de las que hablamos más arriba, la constante ampliación de la convocato-

63 Gelman y Schroeder, 83: 3 (Duke, 2003): 487-520.

64 Ver al respecto el comentario de Santiago Vázquez a modo de reportaje en Ramos Mejía, I, 1927. 
ria, la incorporación de todos los considerados ciudadanos sin importar etnia, riqueza o posición social al mercado electoral, siempre que hicieran acto de fe federal, dejaban entender a las claras la idea de la importancia de los comicios y la asunción de que tal importancia era fundamental para el funcionamiento del sistema. De ello tomaron cuenta los sectores populares y medios, no porque consideraran mayormente que en la arena política se dirimiera algún proyecto. Del apoyo político se obtuvieron, o se obtendrían según el caso, ventajas materiales tanto individuales como comunes para todos, además de la importancia simbólica de pertenecer al colectivo político federal rosista.

En efecto, hemos visto que la comunidad de Azul, que había recibido tierras desde principios de la década de 1830, se distinguía del resto de otros partidos meridionales por su mayor participación electoral, lo que, dado la lista única, se convertía en un apoyo incondicional al rosismo. Asimismo, era Azul en 1839 el partido cuyas desigualdades sociales estaban menos marcadas en todo el sur e incluso equiparable a los partidos de menor desigualdad de toda la campaña, a juzgar por la distribución de la riqueza ${ }^{65}$. Es decir, un partido de pequeños y medianos productores-propietarios. Podríamos decir entonces que el apoyo al sistema era la recompensa por el otorgamiento de tierras públicas y otros bienes como ganado, dentro de un esquema de poder más amplio, que incluyó el nombramiento de autoridades políticas, religiosas y militar-milicianas afectas al régimen cuando no parientes directos de Rosas, que fueron en gran medida receptoras de estos campos; la instalación de las tribus indígenas más fieles en Tapalqué; la exención del servicio militar provincial y externo a los vecinos-milicianos con territorialidad regional; entre otras prácticas discursivas y de adoctrinamiento social, que coadyuvaron a crear un vecindario adepto que legitimó a la causa mediante el voto y el servicio de armas hasta su caída en $1852^{66}$.

En el caso de Quilmes, los apoyos también se pueden encontrar entre los sectores medios, los pequeños productores y propietarios del partido. Hemos probado en otro trabajo que estos sectores fueron los que conformaron el núcleo central de los funcionarios rosistas del período, los alcaldes y tenientes de alcalde, e incluso los jueces de paz de la década de 1840. Como vimos también, un sector de la población del partido fue considerado unitario por sus propios paisanos, por lo que las divisiones fueron más profundas. Para ese núcleo que se mantuvo fiel el premio fue posterior al apoyo, si bien se pueden entender como beneficiosas prerrogativas las que disfrutó el conjunto de los

65 Gelman y Santilli, 2006: cap. 2.

66 Lanteri, 2008b. 
pequeños productores que abastecían a la ciudad merced a las ventajas otorgadas mediante la ley de Aduanas a los labradores. Pero los beneficios a título individual se produjeron con posterioridad a ese apoyo, en la década de 1840, cuando el gobierno exceptuó de algún impuesto a los habitantes que participaron de las luchas contra los levantamientos unitarios, aunque en realidad se extendió a todo aquel que pudo demostrar comunión de fe federal. La ley le confirió la prerrogativa de otorgar la exención al juez de paz, poder local por antonomasia, con lo cual dejó en manos de la comunidad la regulación del beneficio, es decir, el juzgamiento de cuán buen federal se había comportado el solicitante. Y como a su vez el juez de paz era la autoridad electoral y debía demostrar su convocatoria ante sus jefes, nuestra presunción es que la exención era objeto de negociación a cambio del apoyo demostrado o del futuro apoyo en el ámbito eleccionario ${ }^{67}$.

En definitiva, dos conclusiones generales se pueden obtener de nuestro estudio. La primera, que vale más para el caso de Quilmes que para Azul-Tapalqué, es que el mentado «unanimismo», es decir, la construcción electoral de una lista única que no permitía la divergencia política, forjada en la ciudad a partir de la asunción del segundo gobierno de $\operatorname{Rosas}^{68}$, también fue objeto de construcción en la campaña. La diferencia es que ello ocurrió antes y de manera menos violenta que en la ciudad, ya que las disputas políticas no pasaban ni pasarían luego por las contiendas electorales. Sin embargo, como hemos visto con el caso de Azul y Tapalqué, en la frontera, por más que el «unanimismo» haya estado cimentado desde 1835 debió ser mantenido regularmente, y las autoridades locales así como las contraprestaciones de bienes por servicios públicos entabladas con diversos sectores sociales fueron medulares en el proceso.

En segundo lugar, comprobamos que existió indudablemente un apoyo popular al rosismo, que excedió con creces a su alianza con las grandes elites económico-sociales, traduciéndose en una masiva y cada vez mayor concurrencia a los actos electorales por parte de grupos que excedieron a los vecinos formalmente habilitados por la ley de 1821, como dependientes, indios, etc., amén de otras manifestaciones que no hemos tratado en este artículo, como fiestas cívicas, liturgias religiosas, etc. La contrapartida de este apoyo estuvo dada, entre otras motivaciones, por los beneficios obtenidos tanto a nivel general, como colectivo social, como a nivel individual, en la obtención de tierras,

67 Hemos demostrado el importante estipendio económico que esto significaba para los beneficiarios; sin embargo, no representaba un esfuerzo financiero para el Estado. Santilli, 12 (Rosario, 2008a): 60-63.

68 Ternavasio, 2002. 
de exenciones impositivas y en el otorgamiento de protección a la producción y propiedad de estos pequeños y medianos productores; ciudadanos consagrados, que fueron centrales en la construcción del republicanismo vernáculo mediante su praxis social.

\section{BIBLIOGRAFÍA}

Annino, Antonio (coord.), Historia de las elecciones en Iberoamérica, Buenos Aires, FCE, 1995.

Barral, María Elena y Fradkin, Raúl, «Los pueblos y la construcción de las estructuras de poder institucional en la campaña bonaerense (1785-1836)», Boletín del Instituto de Historia Argentina y Americana «Dr. Emilio Ravignani», 27 (Buenos Aires, 2005): 7-48.

Cansanello, Carlos, «Pueblos, lugares y fronteras de la provincia de Buenos Aires en la primera parte del siglo XIX», Jahrbuch Für Geschichte Lateinamerikas, 35 (Colonia, 1998): 159-187.

Cansanello, Carlos, «Itinerarios de la ciudadanía en Buenos Aires. La ley de elecciones de 1821», Prohistoria, 5 (Rosario, 2001): 143-170.

Cansanello, Carlos, De súbditos a ciudadanos. Ensayo sobre las libertades en los orígenes republicanos. Buenos Aires, 1810-1852, Buenos Aires, Imago Mundi, 2003.

Chiaramonte, José Carlos, «Legalidad constitucional o caudillismo: el problema del orden social en el surgimiento de los Estados autónomos del Litoral Argentino en la primera mitad del siglo XIX», Desarrollo Económico, 26/102 (Buenos Aires, 1986): 175-196.

Chiaramonte, José Carlos, Mercaderes del Litoral. Economía y sociedad en la provincia de Corrientes, primera mitad del siglo XIX, México, FCE, 1991.

Chiaramonte, José Carlos, Ciudades, provincias, Estados: Orígenes de la Nación Argentina (1800-1846), Buenos Aires, Ariel, 1997.

Chiaramonte, José Carlos, «Ciudadanía, soberanía y representación en la génesis del Estado argentino (c. 1810-1852)», Sábato, Hilda (coord.), Ciudadanía política y formación de las naciones. Perspectivas históricas de América Latina, México, Colmex-FCE, 1999: 94-116.

Di Meglio, Gabriel, «La mazorca y el orden rosista», Prohistoria, 12 (Rosario, 2008): 69-90.

Echeverría, Olga y Lionetti, Lucía, «La complejidad de lo político», Anuario IEHS, 18 (Tandil, 2003): 191-199.

Fradkin, Raúl, La historia de una montonera. Bandolerismo y caudillismo en Buenos Aires, 1826, Buenos Aires, Siglo XXI, 2006. 
Galimberti, Vicente A., «Los procesos electorales en la Villa de Luján entre la revolución y la consolidación del rosismo, 1815-1842», Tesis de Licenciatura, UNLu, 2009.

Garavaglia, Juan Carlos, «Elecciones y luchas políticas en los pueblos de la campaña de Buenos Aires: San Antonio de Areco (1813-1844)», Boletín del Instituto de Historia Argentina y Americana «Dr. Emilio Ravignani», 27 (Buenos Aires, 2005): 49-74.

Gelman, Jorge, «Un gigante con pies de barro. Rosas y los pobladores de la campaña», Goldman, Noemí y Salvatore, Ricardo (comps.), Caudillismos rioplatenses. Nuevas miradas a un viejo problema, Buenos Aires, Eudeba, 1998: 223-240.

Gelman, Jorge, «Crisis y reconstrucción del orden en la campaña de Buenos Aires. Estado y sociedad en la primera mitad del siglo XIX», Boletín del Instituto de Historia Argentina y Americana «Dr. Emilio Ravignani», 21 (Buenos Aires, 2000): 7-31.

Gelman, Jorge, «Unitarios y Federales. Control político y construcción de identidades en Buenos Aires durante el primer gobierno de Rosas», Anuario IEHS, 19 (Tandil, 2004a): 359-390.

Gelman, Jorge, «La construcción del orden postcolonial. El "sistema de Rosas" en Buenos Aires, entre la coerción y el consenso», Tiempos de América, 11 (Castellón, 2004b): 27-44.

Gelman, Jorge y Schroeder, María Inés, «Juan Manuel de Rosas contra los estancieros: los embargos a los 'unitarios' de la campaña de Buenos Aires», Hispanic American Historical Review, 83: 3 (Duke, 2003): 487-520.

Gelman, Jorge y Santilli, Daniel, De Rivadavia a Rosas. Desigualdad y crecimiento económico. Historia agraria del capitalismo pampeano, 3, Buenos Aires, Siglo XXI, 2006.

Goldman, Noemí (dir.), Nueva Historia Argentina. Revolución, República, Confederación (1806-1852), 3, Buenos Aires, Sudamericana, 1998.

Goldman, Noemí y Salvatore, Ricardo (comps.), Caudillismos Rioplatenses. Nuevas miradas a un viejo problema, Buenos Aires, Eudeba, 1998.

Halperín Donghi, Tulio, «La expansión ganadera en la campaña de Buenos Aires (1810-1852)», Desarrollo Económico, 3 (Buenos Aires, 1963): 57-110.

Halperín Donghi, Tulio, Revolución y guerra. Formación de una elite dirigente en la Argentina criolla, Buenos Aires, Siglo XXI, 1972.

Infesta, María Elena, «Propiedad rural en la frontera. Azul, 1839», Barba, Enrique, In Memoriam. Estudios de Historia, Buenos Aires, Banco Municipal de La Plata, 1994: 269-286.

Infesta, María Elena, La pampa criolla. Usufructo y apropiación privada de tierras públicas en Buenos Aires, 1820-1850, La Plata, AHPBA, 2003. 
Joseph, Gilbert and Nugent, Daniel (eds.), Everyday forms of state formation. Revolution and the negotiation of rule in modern Mexico, Durham and London, Duke University Press, 1994.

Lanteri, Sol, «Estado, tierra y poblamiento en la campaña sur de Buenos Aires durante la época de Rosas. La frontera del arroyo Azul», Anuario de Estudios Americanos, 2/62 (Sevilla, 2005): 251-283.

Lanteri, Sol, «Una verdadera "isla en el nuevo sur”. Las donaciones condicionadas en el arroyo Azul durante el rosismo», Mundo Agrario. Revista de estudios rurales, 14 (La Plata, 2007) www.mundoagrario.unlp.edu.ar

Lanteri, Sol, «¿Una frontera bárbara y sin instituciones? Elecciones y clientelismo en la formación del Estado provincial durante el gobierno de Rosas», Prohistoria, 12 (Rosario, 2008a): 15-40.

Lanteri, Sol, «Un vecindario federal. La construcción del orden rosista en la frontera sur de Buenos Aires. Un estudio de caso (Azul y Tapalqué)», Tesis Doctoral (inédita), IEHS-UNCPBA, Tandil, 2008 b.

Lanteri, Sol y Pedrotta, Victoria, «Mojones de piedra y sangre en la pampa bonaerense. Estado, sociedad y territorio en la frontera sur durante el siglo XIX», Estudios Trasandinos, 15/1 (Mendoza, 2009): 101-129.

Lynch, John, Juan Manuel de Rosas, Buenos Aires, Hyspamérica, 1986.

Maeder, Ernesto, Evolución demográfica argentina de 1810 a 1869, Buenos Aires, Eudeba, 1969.

Malamud, Carlos (coord.), Legitimidad, representación y alternancia en España y América Latina: las reformas electorales (1880-1930), México, Colmex-FCE, 2000 .

Moreno, José Luis y Mateo, José, «El "redescubrimiento" de la demografía histórica en la historia económica y social», Anuario IEHS, 12 (Tandil, 1997): 35-55.

Pedrotta, Victoria, «Las sociedades indígenas del centro de la provincia de Buenos Aires entre los siglos XVI y XIX», Tesis Doctoral (inédita), UNLP, La Plata, 2005.

Prado y Rojas, A., Leyes y decretos de la provincia de Buenos Aires, 1810-1876, III, Buenos Aires, Imprenta del Mercurio, 1871: 354-358.

Quijada, Mónica, Bernand, Carmen y Schneider, Arnd, Homogeneidad y Nación con un estudio de caso: Argentina, siglos XIX y XX, Madrid, CSIC, 2000.

Ramos Mejía, Rosas y su tiempo, I, Buenos Aires, Ed. Científica y Literaria Argentina, 1927.

Ratto, Silvia, "Una experiencia fronteriza exitosa: el "negocio pacífico" de indios en la provincia de Buenos Aires (1829-1852)», Revista de Indias, LXIII/227 (Madrid, 2003): 191-222. 
Rosanvallon, Pierre, La consagración del ciudadano. Historia del sufragio universal en Francia, México, Instituto Mora, 1999.

Sábato, Hilda (coord.), Ciudadanía política y formación de las naciones. Perspectivas históricas de América Latina, México, Colmex-FCE, 1999.

Sábato, Hilda, «On political citizenship in nineteenth-century Latin America», The American Historial Review, 106: 4 (EE.UU., 2001): 1290-1315.

Sábato, Hilda, Pueblo y política. La construcción de la república, Buenos Aires, Capital Intelectual, 2005.

Sábato, Hilda y Lettieri, Alberto (comps.), La vida politica en la Argentina del siglo XIX. Armas, votos y voces, Buenos Aires, FCE, 2003.

Salvatore, Ricardo, «Reclutamiento militar, disciplinamiento y proletarización en la era de Rosas», Boletín del Instituto de Historia Argentina y Americana Dr. Emilio Ravignani, 5 (Buenos Aires, 1992): 25-47.

Salvatore, Ricardo, Wandering Paysanos: state order and subaltern experience in Buenos Aires during the Rosas era, Durham, Duke University Press, 2003.

Santilli, Daniel, «De la dependencia colonial a la "liberación” revolucionaria. La supresión de la reducción de los Quilmes en 1812 a través de sus protagonistas, beneficiados y perjudicados», Anuario IEHS, 22 (Tandil, 2007): 13-40.

Santilli, Daniel, «El unanimismo en la campaña. Las actividades políticas en la zona rural de Buenos Aires entre Rivadavia y Rosas. Quilmes, 1824-1839», Prohistoria, 12 (Rosario, 2008a): 41-67.

Santilli, Daniel, «Desde abajo y desde arriba. La construcción de un nuevo ordenamiento social entre la colonia y el rosismo. Quilmes 1780-1840», Tesis Doctoral (inédita), FFyL-UBA, Buenos Aires, 2008b.

Sevilla Soler, Rosario (coord.), Consolidación republicana en América Latina, Sevi1la, EEHA-CSIC, 1999.

Ternavasio, Marcela, «Hacia un régimen de unanimidad. Política y elecciones en Buenos Aires, 1828-1850», Sábato, Hilda (coord.), Ciudadanía política y formación de las naciones. Perspectivas históricas de América Latina, México, Colmex-FCE, 1999: 119-141.

Ternavasio, Marcela, La revolución del voto. Política y elecciones en Buenos Aires, 1810-1852, Buenos Aires, Siglo XXI, 2002.

Trotta, Miguel, Las metamorfosis del clientelismo político. Contribución para el análisis institucional, Buenos Aires, Espacio, 2003. 
Mapa 1. La campaña de Buenos Aires hacia 1839

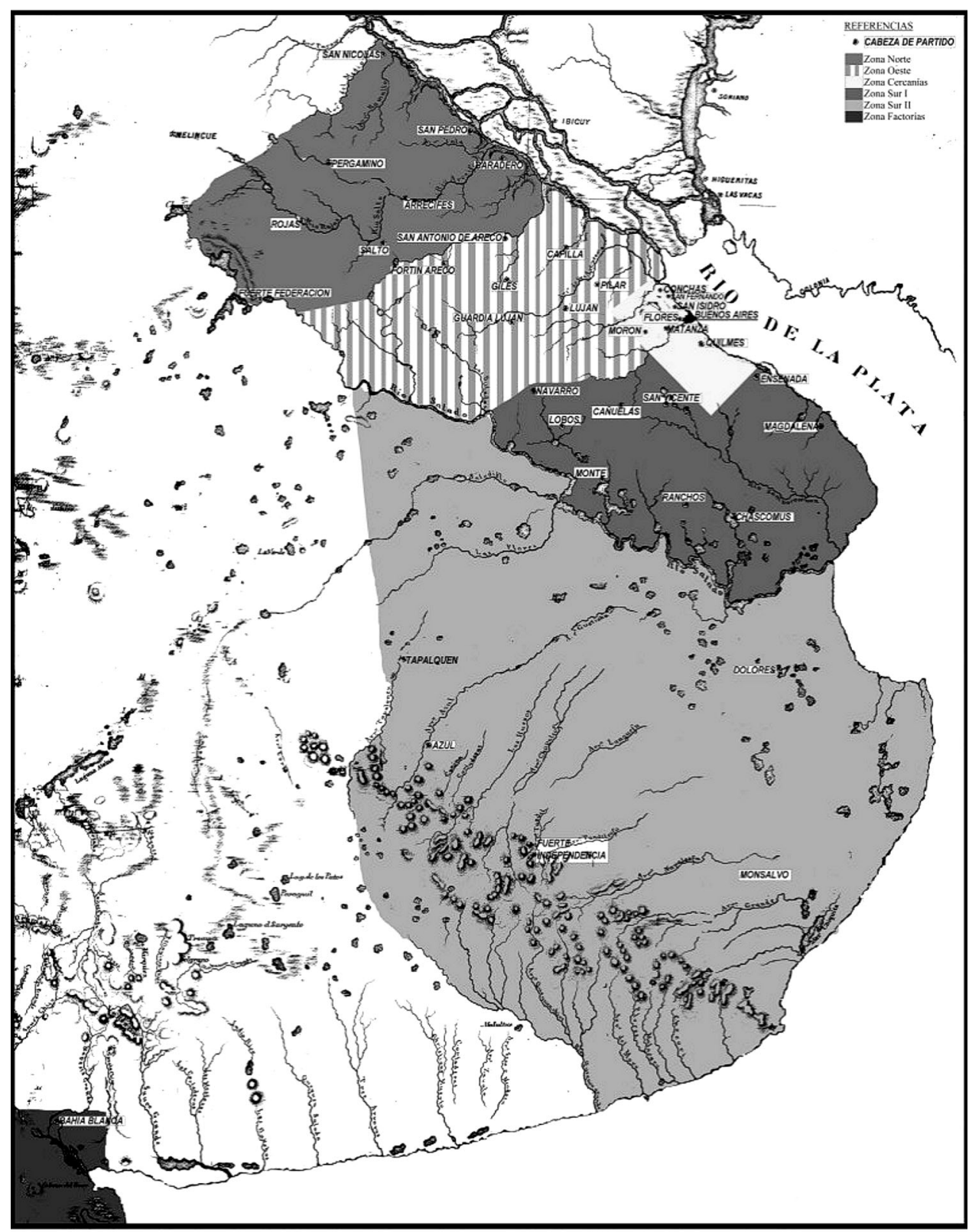

Fuente: Elaboración propia basada en Planos de la Nueva Línea de Frontera sobre la Pampa. Litográfica de Alberto Larsch, Buenos Aires, 1877. 
Fecha de recepción: 29 de julio de 2009

Fecha de aceptación: 19 de febrero de 2010

\section{CONSECRATING THE CITIZENRY: COMPARATIVE ELECTORAL PROCEDURES IN BUENOS AIRES DURING THE FIRST HALF OF THE $19^{\text {th }}$ CENTURY}

The aim of this work is to undertake the first comparative analysis of the electoral practices in the campaign of Buenos Aires from the establishment of the law of «broad» suffrage in 1821 up to and including Rosism, from the study of differentiated political jurisdictions such as the "partido» (minimum political jurisdiction) of Quilmes and Azul-Tapalqué, distanced both geographically and historically. Through correspondence, minutes of meetings and electoral lists, etc., we contrast electoral behaviors related to socio-demographic, economic and cultural aspects, stressing the importance of the middle and subordinate sectors and of the negotiation and consensus during the process.

KEY WORDs: Campaign of Buenos Aires, 1st half of the $19^{\text {th }}$ century, Electoral processes, Negotiation and reciprocities. 